\title{
Relevance-Theoretical Account of Vague Language
}

\author{
Zhi YANG \\ School of Foreign Language, Wuhan Institute of Technology, Wuhan, 430074, China
}

\begin{abstract}
Vagueness, an intrinsic attribute of any natural language, plays an important role in social communication. Why in some cases vague language is more preferable than the exact one and how is it generated? The answer could be well provided by resorting to Relevance Theory, which interprets the vague language either as the instance of loose talk judging the relationship between its propositional form and a thought of the speaker, or as the result of existence of vague concepts according to the relationships between the thought and what it represents.
\end{abstract}

KEYWORD: Vagueness; Root of vagueness; Relevance Theory;

\section{INTRODUCTION}

Traditionally people hold that "good" usage of language involves clarity and precision; and vagueness, ambiguity, imprecision and general woolliness are to be avoided. Thus, Partridge claims that the ideal at which a writer should aim, admittedly it is impossible of attainment, is that he writes so clearly, so precisely, so unambiguously that his words can bear only one meaning to all averagely intelligent readers that possess an average knowledge of the language used [1].

However, this traditional view contradicts actual language usage since vague language is commonly used by people in both daily communication and writing. For example, in writing vague language could be seen everywhere, the saying "to be and not to be" coined by Shakespeare being a typical example of this sort, for which till today no agreement has been reached on its exact meaning. Therefore, vagueness is not the evidence of linguistic inadequacy on the part of the speaker or writer; instead it is the intrinsic attribute of language. And it could be said that any theory of language without having vagueness as an integral part is an incomplete one.

\section{DEFINITON OF VAGUENESS}

The recognition that vagueness is an innate property of natural language has prompted many theorists to the study of vague language, and one of jobs they have commonly undertaken is to define vague language.

Peirce is considered as the originator of the notion of vagueness of language. His admirably clear definition goes as follows: A proposition is vague where there are possible states of things concerning which it is intrinsically uncertain whether, had they been contemplated by the speaker, he would have regarded them as excluded or allowed by the proposition. By intrinsically uncertain we mean not uncertain in consequence of any ignorance of the interpreter, but because the speaker's habits of language were indeterminate; so that one day he would regard the proposition as excluding, another as admitting, those states of things[2].

In his famous book Philosophy of Language, Alston defines vagueness as "a term is said to be vague, if there are cases in which there is no definite answer as to whether the term applies" (this definition is one which defines vagueness by vague term, and at the same time it shows the salient position of vague terms in demonstrating vagueness of language) [3].

Linguist Kempson regards "generality" as one form of "vagueness". In order to see the extent of the problem of distinguishing "ambiguity" from "vagueness", she divides "vagueness" into four types: a) referential vagueness; b) indeterminacy of meaning; c) lack of specification in the meaning of an item; d) disjunction in the specification of the meaning of an item [4].

In fact, many other definitions can be provided besides the above ones, but many more definitions 
can only demonstrate the differences among the scholars in this field. The author dares not to add his own view on the definition of vague language as well as its study scope, but he wants to state that all these differences could be more or less related to one issue: the root of vague language.

\section{ROOT OF VAGUENESS}

Following different tracks, scholars have come up with different views on the source of language vagueness. Some scholars believe that language vagueness is caused by humans' inadequate cognitive ability and the objective or ontological vagueness. Professor Wu Tiepin, a representative of this view, states in his book Fuzzy Linguistics, "While discussing fuzziness, we must distinguish ontological fuzziness and epistemological fuzziness" [5]. While others acknowledge only the epistemological fuzziness, that is, cognitive-related fuzziness and negate the ontological vagueness, since they believe the phenomenon in the world is clear in itself and the objective vagueness is only the reflection of the human cognitive incompetence. The author prefers to take the view that vagueness is related to both objectivity and subjectivity, and also the interaction between objectivity and subjectivity.

\subsection{Vagueness related to objective world}

Everything in the world exists and develops according to its own rule, independent from people's thinking and categorization. And the whole picture of the universe present before people is composed of elements which are connecting and interacting with each other rather than standing discretely. So for some objects and phenomena, it is hard to take an accurate mathematic quantitative method or twovalued logic (either true or false) to describe or identify them. Since there is no clear-cut borderline to separate this object from other objects, vagueness derives from this vague object in the world. When stating "fuzzy set", Zadeh points out that more often than not the classes of objects in the real physical world do not have precisely defined criteria of membership [6]. In this opinion, those unspecified demarcations between animal and plant, among spring, summer, autumn and winter, or vegetable and fruit, etc. in the physical world result in vagueness of word meaning. Thus those symbols, which denote them, are vague. Without these vague objects, there will be no vague meaning.

\subsection{Vagueness related to language user's cognition}

As mentioned above, the view that objective world causes vagueness of language is not widely accepted. It is incompatible with many other theories. For example in the epistemic view, vagueness of language reflects our ignorance of the location of the real boundaries between such as tall and not tall. And degree theories could maintain that there are precise height properties, and that the degree of applicability of our vague predicate tall depends on how they are instantiated. These views do not trace vagueness back to the ontic objects but attribute vagueness to language users or language itself.

On one hand, constrained by the physical environment, perceptive and cognitive ability and many other factors, human being, as the subject of the cognition, could not achieve a thorough and complete understanding of any object at the time he is located. Therefore, the subject would instinctively use imagination, association and speculation to remedy its inadequate knowledge on the object. "The subject, consciously and unconsciously, takes the vague cognition as the bridge leading to clear and precise understanding; this virtually negates the possibility of absolute clearness and accuracy of understanding from the subject's side" [7]. On the other hand, human mental activities include both exact and vague thinking, the latter being an important character of human mind. Vague thinking is the premise and forerunner of exact thinking. As Zadeh puts it, "the difference between human intelligence and automatic intelligence lies in the fact that human's mind is able to think and reason in an unclear, non-quantitative and fuzzy way, this ability enables people to distinguish illegible handwriting, comprehend fuzzy words and focus his attention on the information relevant to the matter" [8].

Since language is the linguistic representation of the thought, the vagueness of thinking will inevitably manifest itself in the language. Therefore, vagueness in lexical meaning represented is not the reflection of vague objects or phenomena, but the fuzzy reflection of objects or phenomenon in human cognition. This could be seen from two sides: a) the limitation of people's knowledge and, b) subjective characteristics of people's psychology. The first case could be illustrated by the word "whale", which people used to refer to an animal in the ocean and categorized into fish. But the science development has proved that the animal denoted by "whale" does not belong to fish. The second case can be proved by the fact that language users sometimes cannot agree whether a symbol could or could not be applied to a phenomenon. Thus the disagreement results in indeterminacy of the symbol (here it refers to the meaning of a term). It can be said that one might draw different boundaries to the same word in different contexts, and different people draw different boundaries to the same word in the same context. 


\subsection{Vagueness from collision between objectiveness and subjectiveness}

As is known to all, the universe is so huge and composed of innumerous things and phenomena, while the language system is limited, so it is completely impossible for a language to identify every entity, event, state, characteristic, and to relate them with separate terms. Besides, the world is constantly changing and developing, making quite new demands on language. For language to be fully useful, therefore, in the sense of being able to describe all of human experiences, it must incorporate built-in flexibility. This flexibility resides, in part, in its capacity of vagueness. People must use so-called "common words" to refer to the infinite varieties of human experiences. This means that such words inevitably have fuzzy boundaries of meanings, because natural phenomena do not neatly occur in well-defined sets. Shi Anshi emphasizes the characteristic "discreteness" of language and believes that limited discrete language results in the vagueness of language [9]. And one salient property of human's cognition is its predilection to organize items into categories, each of which is composed of a "core meaning" consisting of the "clearest cases"(best examples) of the category, surrounded by other category members of the decreasing similarity to that core meaning, and this core meaning is the general term of the category. When a new object appears, people will judge its characteristics and place it into certain category.

Through the foregoing analysis, we may conclude that vagueness is related to not only the objective world, that is, the indeterminate boundary of the object and phenomenon in the world, but also human's cognition or subjective world, what's more, it is also related to the collision between the objective world and subjective world.

\section{RELEVANCE-THEORETICAL ACCOUNT OF LANGUAGE VAGUENESS}

In the last section, roots of language vagueness have been analyzed; this section will be devoted to the explanation of vague language from the perspective of Relevance Theory.

\subsection{Vagueness as instance of loose talk}

Sperber \& Wilson distinguish the descriptive and interpretive language use as: any representation with a propositional form, and in particular any utterance, can be used to represent things in two ways. It can represent some state of affairs in virtue of its propositional from being true of that state of affairs; in this case we will say that the representation is a description, or that it is used descriptively. Or it can represent some other representation which also has a propositional form - a thought, for instance - in virtue of a resemblance between the two propositional forms [10]. And they draw Figure 1 to demonstrate their statement (See Fig. 1).

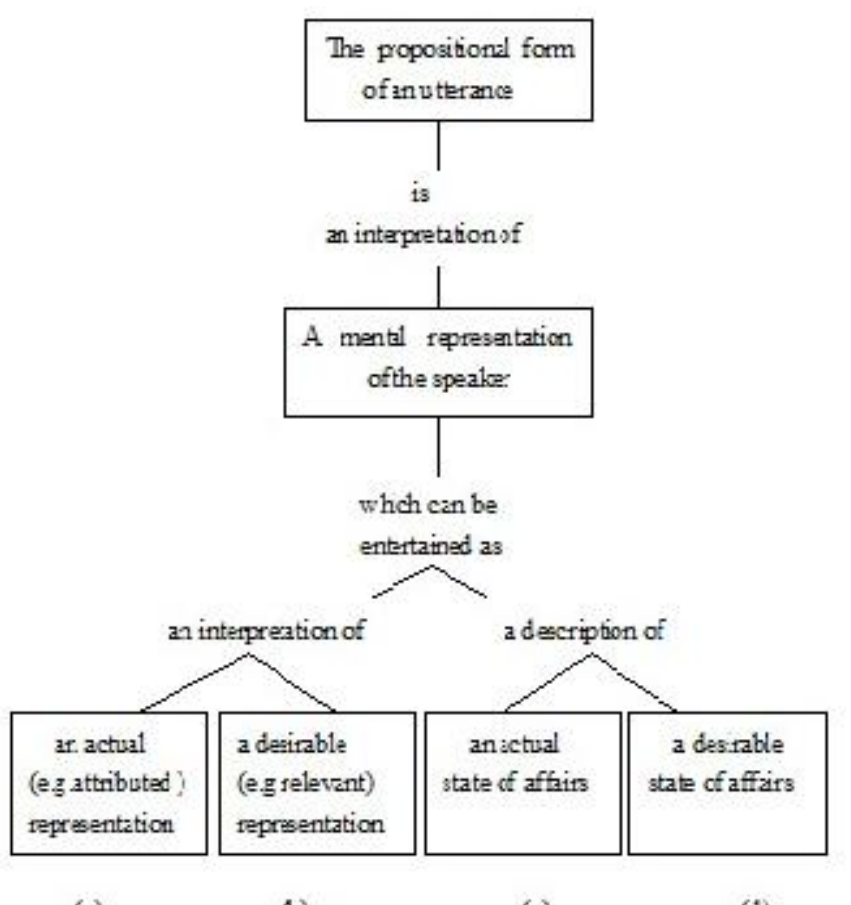

(a)

(b)

(c)

(d)

Figure 1 Aspects of Verbal Communication

According to Sperber \& Wilson, any utterance involves at least two relationships: a relationship between its propositional form and a thought of speaker's, and one of the four possible relationships between the thought and what it represents. Following the notion, they analyze vagueness as an instance of loose talk, which involves less than literal interpretations of thoughts. The author, though adopting relevance theory as the basis for the analysis of vagueness, cannot fully agree with $\mathrm{S} \&$ W's description for vagueness.

From Figure 1, we can see that an utterance is an interpretative expression of a speaker's thought. And this interpretation can be classified as: literal interpretation and less than literal interpretation. An utterance is strictly literal interpretation of the thought if it has the same propositional form as that thought. To say that an utterance is less than strictly literal is to say that its propositional form shares some, but not all, of its logical properties with the propositional form of the thought it is being used to interpret [11]. According to relevance principle, every utterance conveys a presumption of its own optimal relevance. The optimal interpretative expression of a thought should give the hearer information about the thought which is relevant enough to be worth processing, and should require as little processing effort as possible. So what the communicator aims at is optimal relevance, not the literal truth. There are many instances where a literal utterance is not optimally relevant, for example, 
where the effort needed to process it is not offset by the contextual effects obtained from the information conveyed.

When the communicator has a thought $\mathrm{P}$, which, however, is too complex to be represented literally. And a set of assumptions which are manifested by $\mathrm{P}$ and also the communicator intends to communicate to the hearer are all straightforwardly derivable as logical or contextual implications of an easily expressed assumption Q. In this case, though Q is not the communicator's original thought and has some logical and contextual implications which he does not endorse as true and intends the hearer to arrive at, the communicator, guided by the principle of relevance, would still choose $Q$ as the interpretation of his thought $\mathrm{P}$ since they share logical properties, more specifically, logical and contextual implications. Let us see the following example to illustrate the point:

1) A: Xiao Mei has got a gift for you. Have you got it?

B: No. I haven't seen her.

As to the first half of B's response, we can understand it literally that B has never got Mary's gift. But obviously, the same literal truth is not guaranteed by B in the second half of his utterance, that is he has never seen Xiao Mei, which, as a matter of fact, is only one of the some propositions derivable from the second part:

2) P1: I have never seen Xiao Mei before.

P2: I have never seen Xiao Mei since she got a gift for me.

P3: That's why I haven't got her gift for me.

P4: I will get the gift when I see her.

Of course among these implications, logical or contextual, A knows, and what's more, B knows, that A knows which one is to be selected and which one is to be ignored. Thus the speaker will choose the utterance 1B), which is literally false but conveys the same assumption with less processing effort, rather than P2, which is strictly literal and truthful, but entails higher processing effort for the same contextual effect.

In short, loose talk is a variety of the interpretive use of language. It appears that whenever a speaker wants to communicate a set of assumptions and assumes that the exact or literal proposition would be less relevant than another proposition, from which the hearer can derive all these assumptions more economically. In such cases, the speaker does not commit himself to the truth of the proposition literally expressed by his utterance: he is only committed to certain implicatures.

The above elaboration addresses vagueness as an instance of loose talk, which involves less than literal interpretations of thoughts. This, in fact, is dealing with the top part of Figure 1: between the propositional form of an utterance and the thought this utterance is used to represent. But we cannot be satisfied at halting here, since this is just part of the whole story of vagueness. Unfortunately, this is just the $\mathrm{S} \&$ W's proposal for the description of vagueness. In the immediately following section, we will come to discuss the vagueness from the bottom part of Figure 1.

\subsection{Vagueness resulted from vague concepts}

Sperber \& Wilson approach language vagueness only from the first level of relationship: the relationship between the propositional form of the utterance and the thought it interprets; and ignore the second level of relationship: the relationship between the thought and what it represents since, in their eyes, every concept is well-defined, but can be used in a loose way. This view, in fact, contradicts with many philosophers who believe that one important factor for language vagueness is attributed to vagueness in cognition.

Thus, they fail to examine the access the communicator may have to what he is talking about, i.e. the evidential basis of his utterance. Yet, a speaker who utters sincerely the sentence "Lao $\mathrm{Li}$ is fat", with the aim of informing the hearer of $\mathrm{Li}$ 's "fatness", may perceive or have perceived Li's "fatness", or may have a second-hand knowledge about Li.

Let us see the first situation: $\mathrm{Li}$ is a little bit fat, the speaker has a direct perceptual access to Li. When the speaker A sees $\mathrm{Li}$, he has a precise idea, or concept, of the state of Li's figure $\{\mathrm{S}\}$, which, however, is ineffable since the language of thought is richer than natural language. In Relevance Theory, concepts are not only elements of thoughts, but also addresses in memory provided with three entries: a lexical entry, a logical entry, and an encyclopedic entry. The ineffability of concept $\{\mathrm{S}\}$ means its lexical entry is empty. So, if A wants to express the precise thought $\{\mathrm{Li}$ is $\mathrm{S}\}$, he has to find an indirect way of speaking; he is forced to use another concept

\{fat\}, which has a non-empty lexical entry and shares many analytical and contextual features with

$\{\mathrm{S}\}$. Though it seems that this analysis still follows the statement that vagueness derives from the less than literal interpretation of the thought, one should notice that this variety of vagueness is due to the ineffability of some concept, rather than the speakers' intuition to find an economical way to express his thought. Therefore, we can assume the concept $\{$ fat $\}$ itself is vague, and the speaker commits to the truth of proposition of $\{\mathrm{Li}$ is fat $\}$ and asserts to this proposition, different from the case in 4.1, where the speaker does not commit himself to the truth of the proposition literally expressed by his utterance, and is only committed to certain implicatures. 
In the second situation where the speaker has only the second-hand knowledge about $\mathrm{Li}$, the vagueness of concept is more obvious. When A sees Li's figure and informs B, who does not have any perceptual access to $\mathrm{Li}$, he says " $\mathrm{Li}$ is fat" to him. Later on, just in order to inform $\mathrm{C}$, who in turn does not have any perceptual access to $\mathrm{Li}, \mathrm{B}$ says " $\mathrm{Li}$ is fat" to him. If we assume that there are no vague concepts, the analysis would run as follows. After interpreting A's utterance, B cannot have a precise concept of Li's fatness, since he has no perceptual access to Li's figure. In fact, B can only have two types of representations derived from A's utterance: its implicatures and a description $\{\mathrm{A}$ said $\mathrm{Li}$ is fat . Since no precise thought is able to summarize the implicatures of A's utterance, B will naturally opt for $\{\mathrm{A}$ said $\mathrm{Li}$ is fat $\}$. In this perspective, $\{\mathrm{Li}$ is fat $\}$ is a propositional token attributed to A, that the speaker's thought interprets. So, B's utterance can be reduced to an instance of echoic use of propositions. In an echoic use indeed, the propositional form of the utterance interprets one of the speaker's thoughts literally or less than literally, and this thought itself interprets a thought attributed to someone else. B's thought, i.e. $\{\mathrm{Li}$ is fat $\}$ would then make a literal interpretation of the propositional form of his utterance. In other words, we must give up the assumption that, in the case of loose talk, the interpretive use of utterances and concepts is necessarily less than literal.

Let's assume, on the contrary, that there exist vague concepts. Then, $\mathrm{B}$ has in his memory the vague thought $\{\mathrm{Li}$ is fat $\}$, where $\{$ fat $\}$ is a vague concept. B may also keep the evidential source of this information A A said $\mathrm{Li}$ is fat $\}$. Thus, when B utters " $\mathrm{Li}$ is fat", the propositional form of his utterance is a literal interpretation of a thought of B's

$\{\mathrm{Li}$ is fat $\}$, which interprets a propositional token attributed to A. B may also forget the evidential source of his knowledge and consider $\{\mathrm{Li}$ is fat $\}$ as one of his own knowledge; in such a case, his utterance is just an assertion.

\section{CONCLUSION}

Vagueness, one of the important attributes of natural language, is frequently disapproved as the defect by speakers and scholars as well, who, in fact, use it widely in their speaking and writing. Today vagueness has already gained what it deserves, but still many people cannot understand why in many cases it is more preferable than the accurate language. In the paper, the author, based on relevance theory, approaches vague language from the cognition involved in its generation and interpretation. From the relationship of utterance and thought, vagueness can be taken as the instance of loose talk, which involves less than literal interpretations of thoughts. From the relationship of thought and what it represents, vagueness is attributed to the vague concept.

\section{REFERENCES}

[1] Partridge, E. 1947. Usage and Abusage. London: Hamish Hamilton.

[2] Chanell, J. 2000. Vague Language. Shanghai: Shanghai Foreign Language Education Press.

[3] Alston, W. P. 1964. Philosophy of Language. N. J. Prentice-Hall,

[4] Kempson, R. 1977. Semantic Theory. London: Cambridge University Press.

[5] Ping, W.T. 1999. Fuzzy Linguistics. Shanghai: Shanghai Foreign Language Education Press.

[6] Zadeh, L. A. 1987. Fuzzy Sets and Applications: Selected Papers. New York: Wiley.

[7] Ming, L.X. 1986. Fuzziness-A Myth on Human's Cognition. Beijing: Chinese people's Publishing House.

[8] Zadeh, L. A. 1965. Fuzzy Sets. Information and Control.

[9] Shi, S.A. 1991. A discussion on fuzzy semantics with $\mathrm{Fu}$ Dawei. ZhongGuoYuWen (5).

[10]Sperber, D. \& Wilson, D. 1986/1995. Relevance: Communication and Cognition. Oxford UK \& Cambridge USA: Blackwell.

[11]Sperber, D. \& Wilson, D. 2002. Pragmatics, Modularity and Mindreading. Mind and Language, (17): 3-23. 